\title{
Technological Development and its Impact on the Architecture of Sustainable Architectural Form in Iraq
}

\author{
Rabee Jameel Khalid Al-Shammari \\ Department of Architecture, College of Engineering, Wasit University, Kut, Iraq \\ rabee.jameel@uowasit.edu.iq
}

\begin{abstract}
The sustainable architecture is one the key areas of research in the architecture and urban planning. In this paradigm, the architecture is designed and implemented with the focus of the environmental factors. The sustainable architecture keeps track of the environment factors and makes sure that the architecture should be resistant to the natural calamities. The sustainable architecture avoids the negative impacts of the environment on the buildings and town planning objects to have the long life of project. This study underlines the aspects of sustainable architecture with the particular focus in Iraq. With the sustainable development, not only the human growth is concerned but the huge elevation in the national economy is implemented because once the buildings are made with higher lifetime with minimum maintenance, there will be minimum loss and higher efficiency in the natural environment. In addition, the sustainable or green architectures provide the good environment and weather to the citizens that improve their health and minimum expenditures on the medical aspects will be there. The sustainable architecture in Iraq is under implementation with all these points in the consideration, so that, higher efficiency in the work can be obtained. The sustainable architecture is adopted with the renewable resources to have the higher level of optimization in the resources and overall logistics. This manuscript underlines the assorted dimensions and perspectives on the self made homes and the architectures that is integrated and associated with the sustainable architecture.
\end{abstract}

Key words: Case scenarios of sustainable architecture in Iraq, self made architectures, self made homes, sustainable architecture, sustainable architecture in Iraq, sustainable development

\section{INTRODUCTION}

Sustainable architecture (Mahdiraji et al., 2018; Guy and Farmer, 2001; Minke, 2012) is engineering that looks to limit the negative ecological effect of structures by productivity and balance in the utilization of materials, vitality and advancement space and the biological community on the loose (Zolfani et al., 2018; Fuchs et al., 2008 s). Sustainable engineering utilizes a cognizant way to deal with vitality and natural protection in the plan of the manufactured environment Fig. 1.

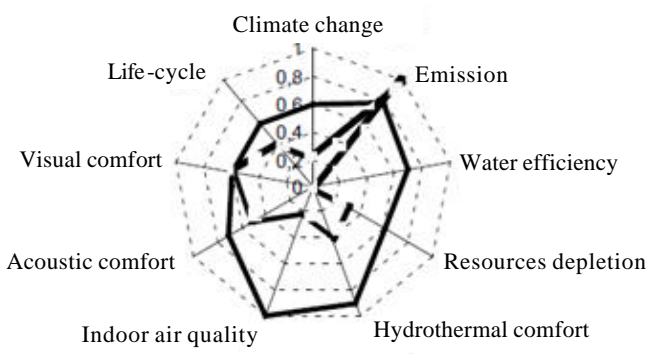

The possibility of supportability or environmental outline is to guarantee that our activities and choices today don't hinder the chances of who and what is to come.

A few cases of sustainable building materials incorporate reused denim or blown-in fiber glass protection, economically collected wood, trass, linoleum, sheep fleece, concrete (high and ultra high performance roman self-mending concrete), boards produced using paper chips, prepared earth, smashed earth, mud, vermiculite, flax linnen, sisal, see grass,

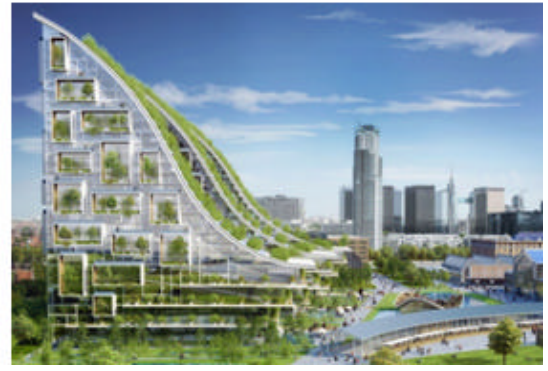

Fig. 1: Sustainable architecture 
extended mud grains, coconut, wood fiber plates, calcium sand stone, privately got stone and shake and bamboo, which is one of the most grounded and quickest developing woody plants and non-lethal low-VOC pastes and paints. Vegetative cover or shield over building envelopes additionally, helps in the same. Paper which is created or produced out of backwoods wood is as far as anyone knows $100 \%$ recyclable. Accordingly, it recovers and spares all the timberland wood that it takes amid its assembling procedure ( $\mathrm{Ng}$ and Shahzad, 2018).

\section{MATERIALS AND METHODS}

\section{Key points of the sustainable architecture:}

- Usage of sustainable energy

- Integration of renewable energy

- Recycled materials

- Lower volatile organic compounds

- Waste management

Sustainable architecture in Iraq: Iraq is one of the leading countries focusing on the sustainable development and the design of sustainable architectures. From a research report, the self designed homes which are based on the classical architecture of Iraq are proposed to be the solution for the housing crisis in Mosul (Casey, 2017) (Fig. 2).
The sustainable architecture is more diverted towards the prolonging of the aging in the buildings and towns, so that maximum lifetime can be achieved in the country without any damage. The Kurdistan region is having enormous initiatives whereby the sustainable architectures are integrated (Zebari and Ibrahim, 2016) Fig. 3-6. In Kurdistan, following are the key features implemented for the sustainable architectures:

- Selection of materials

- Insulating the wall sections

- Effective construction mechanisms

- Shading, orientation and ventilation

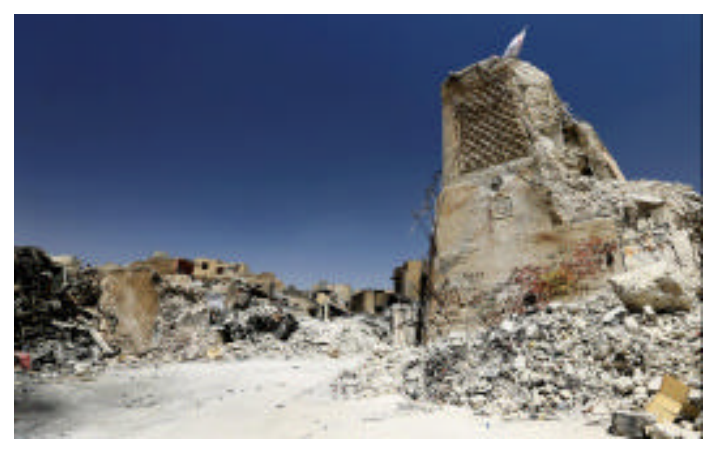

Fig. 2: Self design homes in Mosul

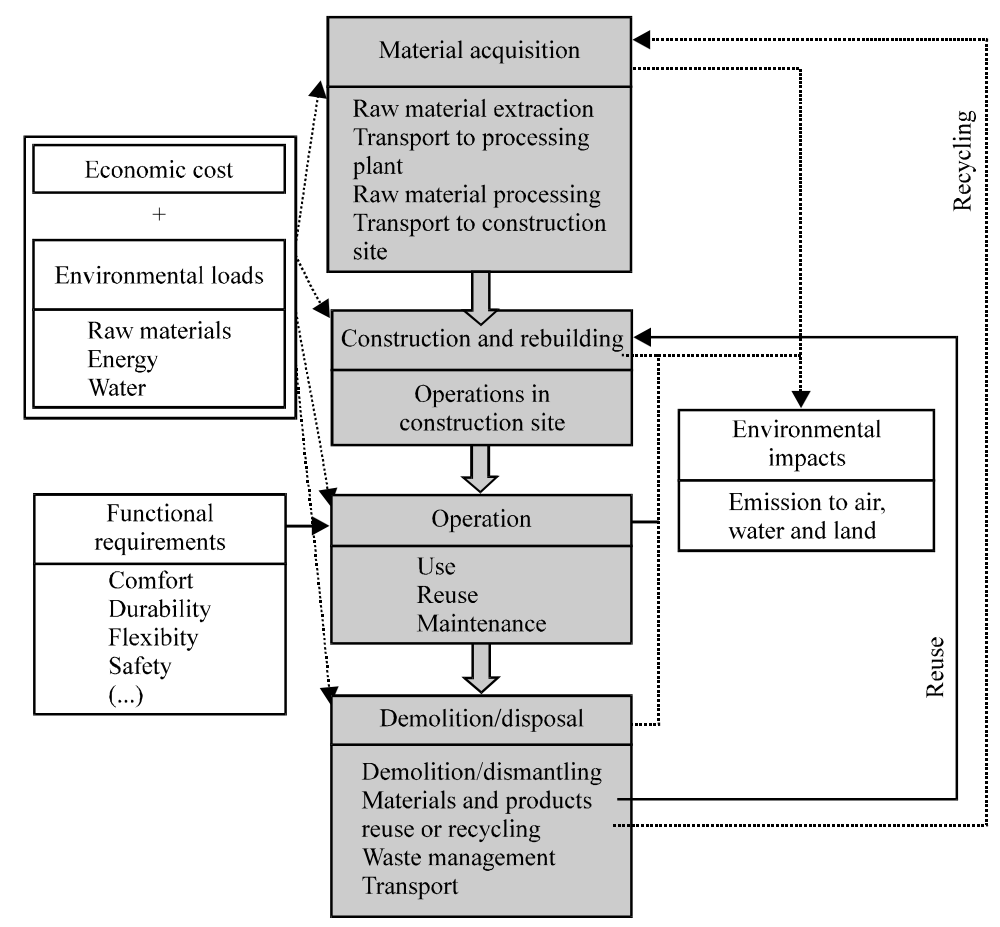

Fig. 3: Model of the sustainable architecture 


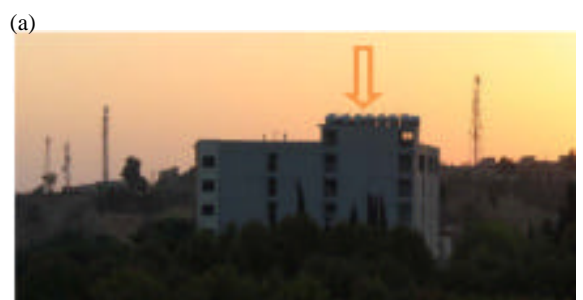

(c)

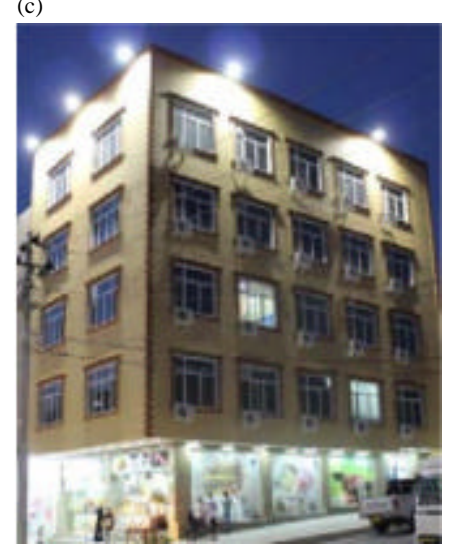

(b)

(d)

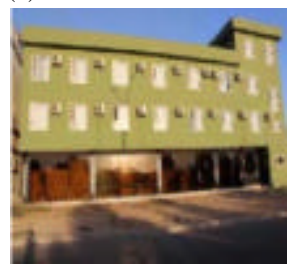

(e)

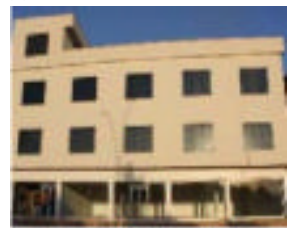

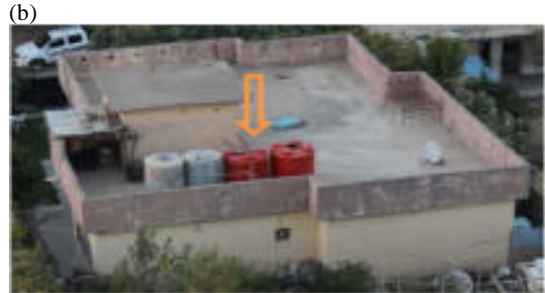

(f)

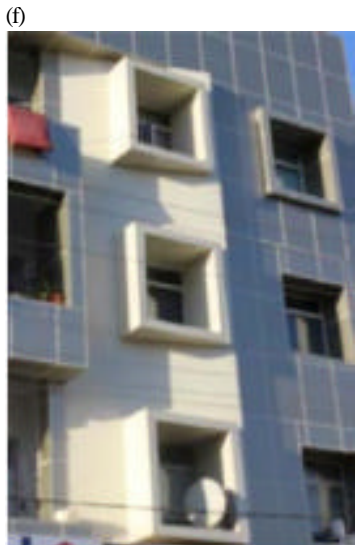

Fig. 4: a-f) Adoption of sustainable architectures in Basra

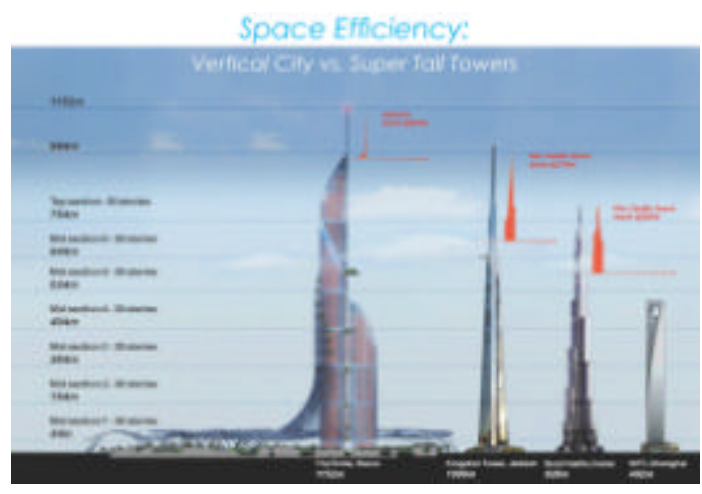

Fig. 5: Sustainable architecture in Basra

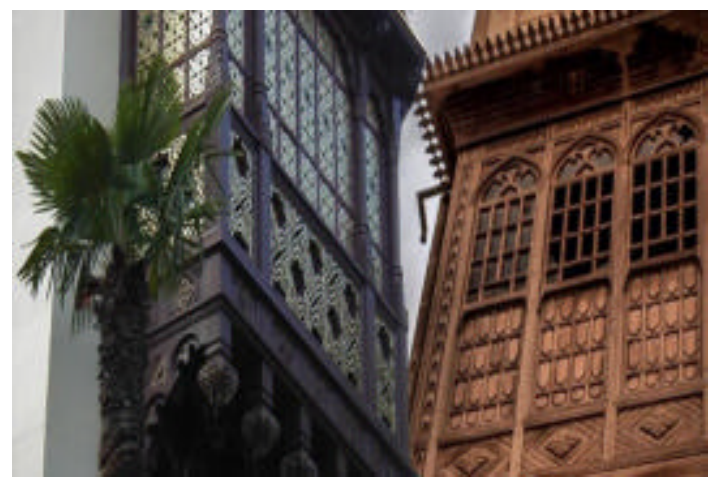

Fig. 6: Shanashel
- Cost effectiveness

- Using plastic water tanks with replacement of zinc water tanks

Basra, Iraq is a growing area for art, sculpture and architecture. Basra is another city in Iraq that is making use of sustainable architectures in the residential as well as commercial buildings. The buildings are created, so that, there is shadow to support the air and natural environment. In addition, the usage of bricks, iron struts and windows are associated with the relation to the natural environment.

\section{RESULTS AND DISCUSSION}

Impact of architectural aspects in development of Iraq: There is huge positive impact of the sustainable architecture in the overall development of Iraq. To cope up with the natural calamities like storm, escalated temperatures, earthquakes, the town planning and architectures are getting reviewed to save the human life and for prolonged age Fig. 7 and 8.

\section{Aggregation method for the sustainable architecture} scoring:

$$
\begin{gathered}
\mathrm{P}_{\mathrm{ENV}}=\sum_{\mathrm{i}=0}^{\mathrm{n}} \mathrm{I}_{\mathrm{ENV}} \cdot \mathrm{W}_{\mathrm{ENV}} \\
\mathrm{SS}=\mathrm{P}_{\mathrm{enV}} \cdot \mathrm{W}_{\mathrm{enV}}+\mathrm{P}_{\mathrm{soc}} \cdot \mathrm{W}_{\mathrm{soc}}+\mathrm{P}_{\mathrm{eco}} \cdot \mathrm{W}_{\mathrm{eco}}
\end{gathered}
$$




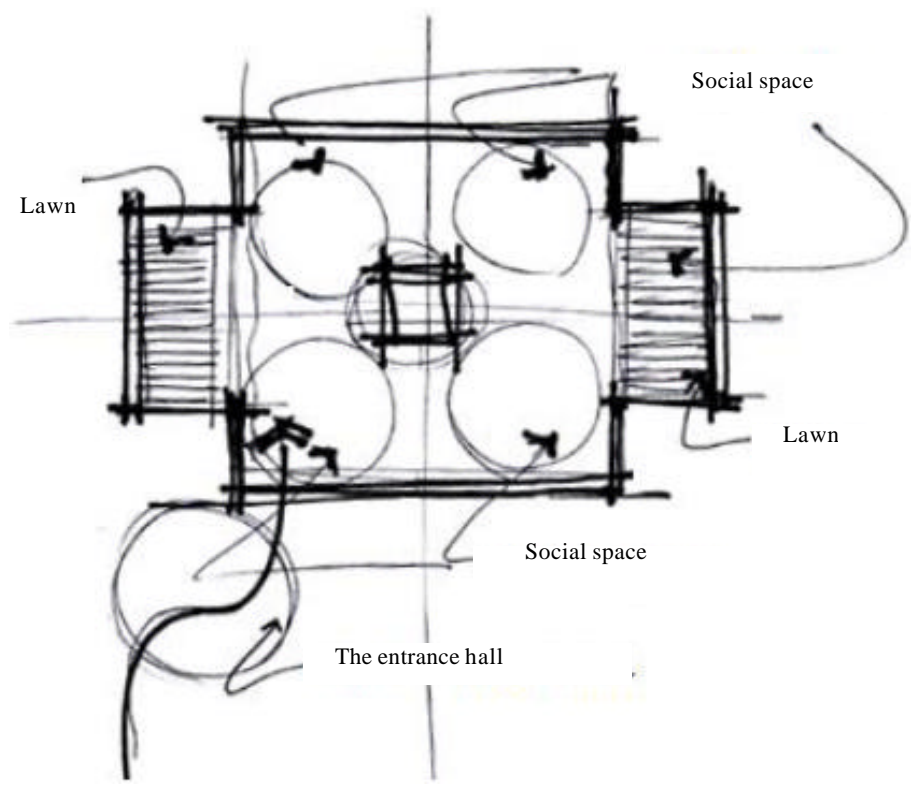

Fig. 7: View of the architecture in traditional buildings

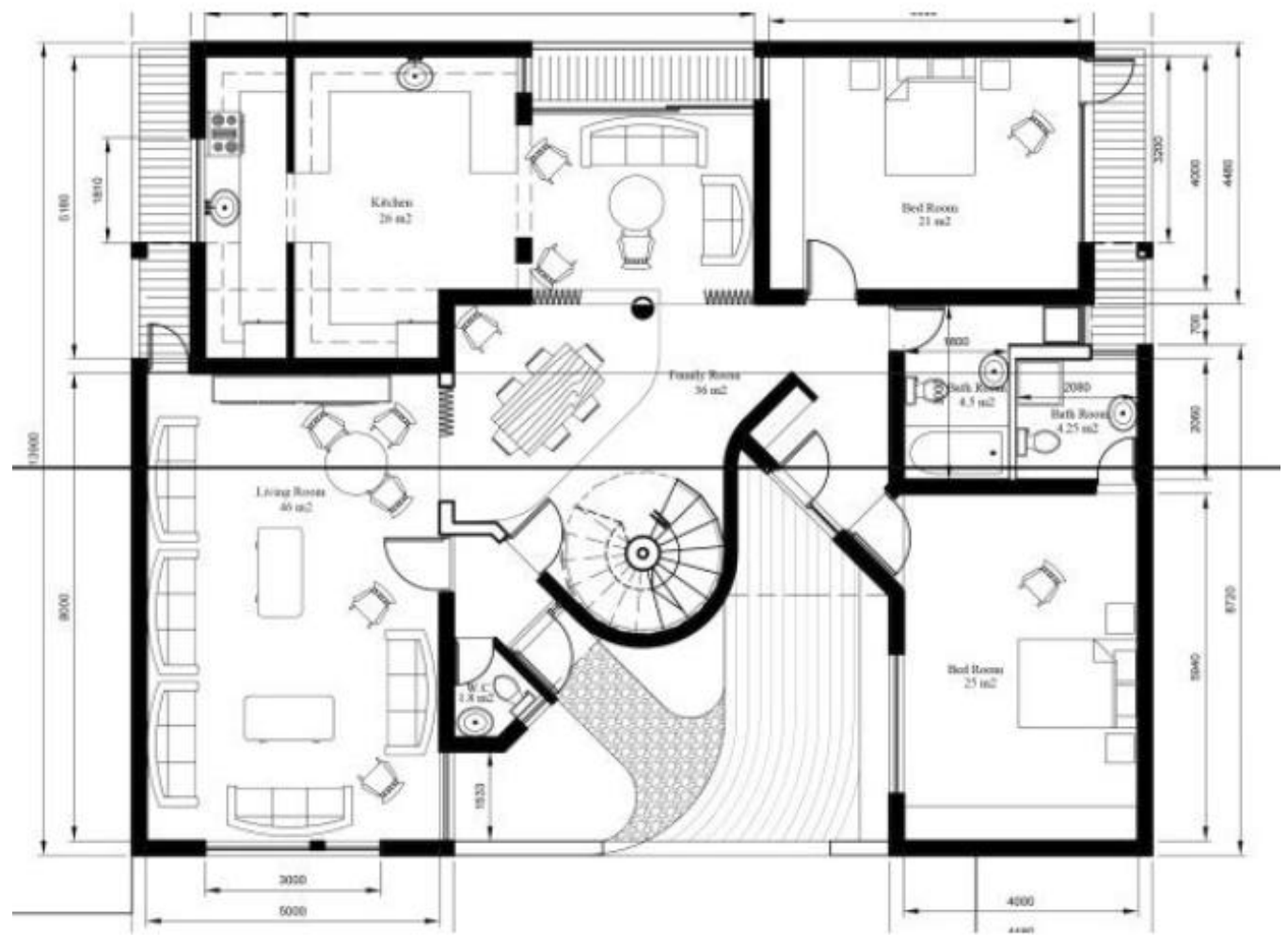

Fig. 8: Modernized view of the architecture in current buildings

Where:

$\mathrm{I} \quad=$ Environmental factor

$\mathrm{W}_{\text {env }}=$ Weight

$\mathrm{P}_{\mathrm{env}}=$ Performance in environment
There are multiple findings and extracts from the researcher of different researchers in this domain. Following are the excerpts. The research by Ayyash (2015) associates the integration of vernacular 
architecture as the sustainable development in the buildings and towns of Iraq. The research presents the case study with multiple perspectives. The main aim and objective of the study is to find out and gaps in the architecture designs in Iraq with the suggestive measures.

The excerpts by Norton (1999) presents the sustainable development with the specific case studies in different countries. The presents the architecture that is gender specific and sensitive towards multiple locations.

Safaee (2009) gives the sustainable architecture titled SHAVADAN with the case scenario of Dezful in the country Iran. The proposed research presents the underground architecture that was given name SHAVADAN with the relative features.

Al-Thahab et al. (2014) presented the social space with the privacy concerns in the novel architectures of Iraq. The detailed view of the historical as well as the current architectures are presented in this researcher. There are enormous advantages of using sustainable designs and architectures:

- Economic benefits

- Energy optimization

- Community and health benefits

- Elevation in the nation's resources

- Optimization of natural resources

Sustainability and urban heritage: The urban heritage is required to be associated with the sustainability, so that, the overall architecture can be retailed to higher lifetime. In addition, the overall lifetime of the architecture is also dependent on the type of design and the components used in the system. The sustainable architecture makes sure that the reusable or renewable resources can be integrated with the elevated level of performance and the lifetime with the enhanced values in the system.

\section{CONCLUSION}

With the increasing scenarios of natural calamities and disasters, there is need to adopt a highly effective mechanism that can save the human life and nation's infrastructure, so that, the overall economy can be escalated. The sustainable architecture is one the key regions of research in the architecture and urban arranging. In this worldview, the architecture is composed and executed with the focal point of the natural elements. The sustainable architecture monitors the earth factors and ensures that the architecture ought to be impervious to the normal cataclysms. The sustainable architecture maintains a strategic distance from the negative effects of nature on the structures and town arranging articles to have the long existence of task. This study underlines the parts of sustainable architecture with the specific concentration in Iraq. With the sustainable improvement, the human development is worried as well as the gigantic height in the national economy is actualized on the grounds that once the structures are made with higher lifetime with least upkeep, there will be least misfortune and higher proficiency in the indigenous habitat. Also, the sustainable or green architectures give the great condition and climate to the subjects that enhance their well being and least uses on the medicinal viewpoints will be there. The sustainable architecture in Iraq is under usage with every one of these focuses in the thought, so, higher productivity in the research can be acquired. Iraq is having many projects with the sustainable architectures, so that, the overall aging of buildings and towns can be improved to highest time span.

\section{REFERENCES}

Al-Thahab, A., S. Mushatat and M.G. Abdelmonem, 2014. Between tradition and modernity: Determining spatial systems of privacy in the domestic architecture of contemporary Iraq. ArchNet. IJAR., 8: 238-250.

Ayyash, A.B., 2015. Sustainability in vernacular architecture of Iraq and its applicability in modern residential buildings in Iraq region. Ph.D Thesis, University of Basrah, Iraq.

Casey, R., 2017. Self-designed homes could provide sustainable future for liberated Mosul. Thomson Reuters News, London.

Fuchs, M., M. Hegger, T. Stark and M. Zeumer, 2008. Energy Manual: Sustainable Architecture. Walter de Gruyter, Berlin, Germany, ISBN:9783764388300, Pages: 280.

Guy, S. and G. Farmer, 2001. Reinterpreting sustainable architecture: The place of technology. J. Arch. Educ., 54: $140-148$.

Mahdiraji, H.A., S. Arzaghi, G. Stauskis and E.K. Zavadskas, 2018. A hybrid fuzzy BWM-COPRAS method for analyzing key factors of sustainable architecture. Sustainability, 10: 1-26.

Minke, G., 2012. Building with Earth: Design and Technology of a Sustainable Architecture. Birkhauser,Basel, Switzerland,ISBN:9783764378738, Pages: 208. 
Ng, K.C. and M.W. Shahzad, 2018. Sustainable desalination using ocean thermocline energy. Renewable Sustainable Energy Rev., 82: 240-246.

Norton, J., 1999. Sustainable architecture: A definition. Habitat Debate, 5: 10-11.

Safaee, M.M., 2009. Shavadan; The sustainable architecture in the city of Dezful in Iran. Proceedings of the 12th International Conference on Associated Research Centers for Urban Underground Space (ACUUS2009), November 17, 2009, Academic Focus, China, pp: 1-8.
Zebari, H.N. and R.K. Ibrahim, 2016. Methods and strategies for sustainable architecture in Kurdistan Region, Iraq. Procedia Environ. Sci., 34: 202-211.

Zolfani, S.H., M. Pourhossein, M. Yazdani and E.K. Zavadskas, 2018. Evaluating construction projects of hotels based on environmental sustainability with MCDM framework. Alexandria Eng. J., 57: 357-365. 